\begin{tabular}{|c|c|}
\hline Title & A nnealing effect on microstructural recovery in $316 \mathrm{~L}$ and $\mathrm{A} 533 \mathrm{~B}$ \\
\hline Author(s) & Hashimoto, N.; Goto, S.; Inoue, S.; Suzuki, E. \\
\hline Citation & $\begin{array}{l}\text { Journal of nuclear materials, } 495,1-5 \\
\text { https://doi.org/10.1016/.jnucmat.2017.07.062 }\end{array}$ \\
\hline Issue Date & $2017-11$ \\
\hline Doc URL & http:/hdl .handle.net/2115/75975 \\
\hline Rights & $\begin{array}{l}\text { () 2017. This manuscript version is made available under the CC-BY-NC-ND } 4.0 \text { license } \\
\mathrm{http}: / / \text { reativecommons.org/icenses/by-nc-nd/4.0/ }\end{array}$ \\
\hline Rights(URL) & http://creativecommons.org/icenses/by-nc-nd/4.0/ \\
\hline Type & article (author version) \\
\hline File Information & TMS_paper_hashimoto_revised.pdf \\
\hline
\end{tabular}

Instructions for use 


\title{
Annealing Effect on Microstructural Recovery in 316L and A533B
}

\author{
N. Hashimoto ${ }^{1}$, S. Goto ${ }^{1}$, S. Inoue ${ }^{1}$, and E. Suzuki ${ }^{2}$ \\ ${ }^{1}$ Hokkaido University, N13W8 Kita-ku Sapporo, Hokkaido, Japan \\ ${ }^{2}$ Japan Atomic Energy Agency, Tokai, Ibaraki, Japan
}

\begin{abstract}
An austenitic model alloy (316L) and a low alloy steel (A533B) were exposed to constant or fluctuating temperature after electron irradiation to a cumulative damage level of 1 displacement per atom. 316L model alloy was exposed to LWR operating temperature during electron irradiation, and were exposed to a higher temperature at a high heating and cooling rates. The annealing experiment after irradiation to $316 \mathrm{~L}$ resulted in the change in irradiation-induced microstructure; both the size and the number density of Frank loop and black dots were decreased, while the volume fraction of void was increased. In the case of A533B, the aging experiment after electron irradiation resulted in the shrinkage or the disappearance of black dots and the growth of dislocation loops. It is suggested that during annealing and/or aging at a high temperature the excess vacancies could be provided and flew into each defect feature, resulting in that interstitial type feature could be diminished, while vacancy type increased in volume fraction if exists.
\end{abstract}

\section{Introduction}

Thermal neutron induces cascade damage and defect clusters would form in structure materials of nuclear power plants. It is well known that the irradiation temperature can have a profound impact on the microstructural evolution in materials [1-10]. Generally, nucleation of defect clusters is maximized at lower temperatures whereas growth of clusters is maximized at higher temperatures. In case the severe accident or some crucial trouble happens and results in the stop of coolant system in operating nuclear reactor, it is predicted that temperature of reactor core would rise up in a short time and then cooled down rapidly or slowly. These varying temperatures allow the possibility of enhanced nucleation and growth of irradiation induced defects compared to a constant-temperature irradiation. Actually, several previous ion irradiation and low-dose neutron irradiation studies [2-10] have found that these temperature variations may exert a significant influence on the microstructural evolution, particularly if the temperature transcends the recovery Stage $\mathrm{V}$ temperature regime (which corresponds to thermal dissociation of small vacancy clusters). The recovery Stage V occurs at $\sim 325^{\circ} \mathrm{C}$ in austenitic stainless steel [11-13]. Void formation was generally enhanced and loop formation suppressed for the preirradiation at low temperatures [2]. One of possible ways to recover the irradiation-induced microstructure could be the thermal aging in appropriate conditions. In fact, previous postirradiation annealing (PIA) experiments have shown the reduction of irradiation hardening [14]. For the PIA experiment, the most important parameter to be considered would be temperature range and annealing time because annealing at high temperatures for irradiated metals can promote void and helium bubble growth $[15,16]$. Helium is insoluble in metals and has strong 
interaction with vacancy, so that upon annealing at high temperature, the radiation induced defects can be removed and helium would form bubbles at locations of low free energy, such as line dislocations and grain boundaries. In 304-type austenitic stainless steel, bubbles become visible (1-4 nm in size) after annealing at $650^{\circ} \mathrm{C}$ [15]. PIA had less effect on recovery for BWR conditions due to thermally-sensitization during annealing, but a clear effect on microstructure and hardness for PWR conditions [17]. The PIA experiments were previously performed on 304 $[17,18]$ and $316[15,19]$ type stainless steels irradiated to moderate doses of 25 dpa and on 316 CW type stainless steel irradiated in a commercial reactor to $80 \mathrm{dpa}$ [20]. In this paper, we are focusing on microstructure change in 316L and A533B, which is used as shroud and pressure vessel in Light Water Reactor (LWR), at the low doses of 1 dpa by electron beam irradiation. The important parameters of microstructure change are the size and the density of loops, cavities, and black dots during irradiation and annealing.

\section{Experimental procedure}

The materials used for this study were 316L model austenitic stainless steel and A533B low alloy steel, which is used as shroud and pressure vessel in Light Water Reactor (LWR). Tables 1 and 2 indicate chemical compositions of 316L and A533B, respectively. 316L were arc-melted and rolled down to $0.2 \mathrm{~mm}$ in thick. TEM discs of $3 \mathrm{~mm}$ in diameter were punched out and solution-annealed at $1080^{\circ} \mathrm{C}$ for $20 \mathrm{~min}$ in vacuum, followed by electro-polishing for irradiation experiment. Samples were used for electron irradiation experiment on the purpose of in-situ observation of microstructure change. The in-situ electron irradiation experiment was performed for 316L and A533B by a high voltage electron microscope (HVEM), JEM-ARM-1300 (JEOL) operated at $1250 \mathrm{kV}$ at Hokkaido University. The observed beam direction was kept near $\mathrm{B} \approx[001]$. The dose rates were from $1 \times 10^{-4}$ to $1 \times 10^{-3} \mathrm{dpa} / \mathrm{s}$. Irradiation was performed in relatively thick regions with low dislocation density to achieve less effect of surface and dislocation on point defect flow to loop. The irradiation conditions were summarized in Table 3. After in-situ electron irradiation, heat treatment experiments were performed in column of microscope. When the severe accident happened, the average temperature of reactor pressure vessel was estimated about $700^{\circ} \mathrm{C}$ in maximum, so that the temperature of annealing experiment was set $700^{\circ} \mathrm{C}$ for core material (shroud: $316 \mathrm{~L}$ ) and $500^{\circ} \mathrm{C}$ for outside material (pressure vessel: A533B). Histories of heat treatment experiment for 316L and A533B were shown in Figure 1 and 2 , respectively.

\section{Results}

\subsection{Microstructural evolution in irradiated 316L during heat treatment}

Solution-annealed 316L has less dislocation lines and none of precipitates in matrix. Typical microstructures of electron-irradiated $316 \mathrm{~L}$ heated up to $700^{\circ} \mathrm{C}$ and cooled down to $290^{\circ} \mathrm{C}$ are shown in Figure 3. In this irradiation condition, both interstitials and vacancies can move appreciably. During in-situ electron irradiation to $1 \mathrm{dpa}$ at $290^{\circ} \mathrm{C}$, the formation of faulted dislocation loops (Frank loops), voids, and interstitial type black dots were observed. In Figure 3, 
a dark field image obtained by using the streaks in diffraction pattern, which were relrods from Frank loops. Examination of the relrod images allows the estimation of number density and average size of Frank loops to be about $2.8 \pm 0.5 \times 10^{22} \mathrm{~m}^{-3}$ and $17.2 \pm 0.5 \mathrm{~nm}$, respectively. Voids can be observed using the under-focus (white contrast) and over-focus (black contrast) imaging technique as shown in Figure 4, and black dots were recognized not as edge-on but tiny round feature in bright field image. Irradiation-induced defects in electron- irradiated 316L before and after annealing were summarized in Table 3. After annealing shown in Fig. 3, the average size and the number density of Frank loop and black dot were decreased, while the volume fraction of voids seemed to be increased.

\subsection{Microstructural evolution in irradiated A533B during heat treatment}

Figure 5 shows microstructural evolution in A533B irradiated to $1 \mathrm{dpa}$ at $80^{\circ} \mathrm{C}$, and then, heating up to 400,450 , and $500^{\circ} \mathrm{C}$ and cooling down to $80^{\circ} \mathrm{C}$. We set the irradiation temperature to be $80^{\circ} \mathrm{C}$ in order to introduce appropriate number and size of dislocation loop for in-situ observation. During irradiation, black dot formation was first observed in the early stage of irradiation (0.01 dpa). Size of black dot increased to a couple of $\mathrm{nm}$ in maximum. On the other hand, dislocation loop started to be observed at about $0.1 \mathrm{dpa}$, and a part of them showed 1D motion. It is interesting that black dots hardly changed to larger loops, meaning that all the black dots could not change to dislocation loop. In addition, those black dots and loops did not react neither each other nor with dislocation lines. Finally, the number density of black dots and loops was $4-5 \times 10^{22} \mathrm{~m}^{-3}$. After the electron irradiation at $80^{\circ} \mathrm{C}$, irradiation temperature was raised up to 400,450 , and $500^{\circ} \mathrm{C}$ for $10 \mathrm{~min}$. and aged for $20 \mathrm{~min}$. in microscope. Size and number density of dislocation loops in each condition were summarized in Table 4. During aging, the irradiationinduced black dots were shrunk and disappeared, while loops were grown in all the aging conditions. The final number density of loops was one order less than that before aging.

\section{Discussion}

Electron irradiation experiment for 316L resulted in the formation of a high number density of Frank loops, voids, and interstitial type black dots. The values of measured size and number density of each feature seemed to be reasonable compared with previous studies [15,19-22]. Generally, neutron irradiation to 316L at relatively low temperature produced a high number density $\left(<10^{23} \mathrm{~m}^{-3}\right)$ of very small defect clusters: black dots and voids $(<3 \mathrm{~nm})$. It has been reported $[23,24]$ that neutron irradiation at $320^{\circ} \mathrm{C}$ created both vacancy and interstitial type loops. In this experiment, however, a high density of voids was observed instead of vacancy type loops. During electron irradiation, vacancies and interstitials can be introduced as Frenkel pairs, and the concentration of both defects increase with irradiation time. After the recombination of vacancies and interstitials, interstitial type clusters (black dots and dislocation loop) starts to form in matrix, followed by the formation of vacancy type clusters (voids). In this work, the irradiation and annealing experiments were performed at temperatures both interstitial and vacancy are mobile. Since none of interstitials would be introduced during annealing, only vacancies can move in matrix and flow into sinks, such as surface, grain boundaries, and defect features (black dots, 
Frank loops, and voids). After the annealing experiment, the average size and the number density of Frank loop, black dot, and void decreased, while the volume fraction of voids seemed to increase. This probably means that the excess vacancies could exist in matrix and flew into defect features in the temperature range between $290^{\circ} \mathrm{C}$ and $700^{\circ} \mathrm{C}$. One of possible reasons for the existence of excess vacancies could be the increase in the thermal balance vacancies.

Thermal vacancy concentration $c_{v}$ in metal can be simply calculated using the formula:

$c_{v}=A_{v} \exp \left(-E_{v}{ }^{F} / k T\right)$

where $k$ is the Boltzmann constant, $T$ the annealing temperature, $E_{v}{ }^{F}$ the formation energy of vacancy, and $A_{v}$ the constant ( $\approx 1$ for metal). According to this formula, the amount of vacancy at $700^{\circ} \mathrm{C}$ was calculated to be about $10^{16} \mathrm{~m}^{-3}$, which was eleven orders higher value than that at $290^{\circ} \mathrm{C}$. Those would be provided from grain boundary and thermodynamically unstable small voids, which resulted in the disappearance or shrinkage of voids. However, the calculated amount of thermal vacancy seems to be too less to drastically change the number density and size of defect features, so that more extra vacancies would be provided into irradiation region.

With the assumption that recovery process is driven by diffusion, the iron diffusion length is calculated using the formula:

$d=(D t)^{1 / 2}$

with $t$ the annealing time and $D$ the iron self-diffusion coefficient $\left(\mathrm{m}^{2} / \mathrm{s}\right)$ given by:

$D=D_{0} \exp (-Q / k T)$

where $k$ is the Boltzmann constant, $T$ the annealing temperature and $Q$ the migration energy. With values taken from Busby et al. [14]: $Q=1.29 \mathrm{eV}$ and $D_{0}=1.54 \times 10^{-6} \mathrm{~m}^{2} / \mathrm{s}$, the diffusion distance of Fe in a short duration of heating and cooling for $\sim 5$ min each was estimated to be about $320 \mathrm{~nm}$, which is sufficient time for defect migration in the irradiated area of TEM sample. The thickness of TEM sample used for in-situ experiment was about $300 \pm 10 \mathrm{~nm}$, so that vacancies could be provided from TEM specimen surface. In addition, some vacancies could diffuse into the irradiation region from outside of the region. The annealing experiment resulted in the decrease in number density of black dots, Frank loops, and voids, while the increase in volume fraction of voids, due to the flux of thermal balanced vacancies and vacancies from surface to defect features during heating up to and cooling down process.

In the case of electron-irradiated A533B, irradiation-induced defect features are totally different from that in 316L. As-received A533B includes dislocation lines and precipitates in matrix, which could act as the sink of point defects such as vacancies and interstitials. During electron-irradiation at $80^{\circ} \mathrm{C}$, a high number density of black dots observed in the early stage of irradiation ( $0.01 \mathrm{dpa})$. The size of these black dots was too small to be recognized as dislocation 
loops. While, no voids were observed in matrix. This result has a good agreement with previous study [26]. In this experiment, two different types (small and large) of black dots were experimentally confirmed. It is noted that some black dots were stable and never change their size during irradiation to $1 \mathrm{dpa}$, while some showed 1D motion. It means that a part of black dots grew and change to dislocation loops with a Burgers vectors $\boldsymbol{b}$. A MD simulation study [27, 28] reported that small clusters of $\langle 100\rangle$ crowdions, which can be obtained after relaxation of initially created sets of $\langle 110\rangle$ dumbbells, had relatively high stability. Furthermore, in case of larger clusters (more than about 7 SIAs), only two configurations are stable, namely sets of $<111>$ or $<100>$ crowdions, and they may act as nuclei of interstitial dislocation loops with Burgers vectors $\boldsymbol{b}$ equal to $(1 / 2)<111>$ or $<100>$, respectively [29]. Aging experiment after electron irradiation resulted in the decrease in number density and the increase in size of black dots, as it were, the shrinkage or disappearance of black dots and the growth of dislocation loops. This phenomenon is quite similar to that observed in 316L. The evolution of defect features during aging would be basically controlled the amount of excess vacancy.

\section{Summary}

316L and A533B were exposed to constant or fluctuating temperature after electron irradiation to a cumulative damage level of $1 \mathrm{dpa}$. The annealing after irradiation to 316L resulted in the change in irradiation-induced microstructure; both the size and the number density of Frank loop and black dots were decreased, while the volume fraction of void was increased. In the case of A533B, two different types of black dots were experimentally confirmed. The aging experiment after electron irradiation resulted in the shrinkage or the disappearance of black dots and the growth of dislocation loops. It is suggested that during annealing and/or aging at a high temperature the excess vacancies could be provided and flew into each defect feature, resulting in that unstable interstitial type feature could be diminished, while vacancy type increased in volume fraction if exists.

\section{Acknowledgements}

The authors were thankful to Dr. Ohkubo of Japan Atomic Energy Agency for operating TIARA facility at Takasaki and to Mr. Ohkubo for operating the High Voltage Electron Microscope at Hokkaido University.

\section{References}

1) M. Kiritani, J. Nucl. Mater. 160 (1988) 135-141.

2) M. Kiritani, T. Yoshiie, S. Kojima, Y. Satoh, and K. Hamada, J. Nucl. Mater. 174 (1990) 327351.

3) M. Kiritani, T. Endoh, K. Hamada et al., J. Nucl. Mater. 179-181 (1991) 1104-1107.

4) M. Kiritani, T. Yoshiie, M. Iseki et al., J. Nucl. Mater. 212-215 (1994) 241-245.

5) N. Yoshida, Q. Xu, H. Watanabe, Y. Miyamoto, and T. Muroga, J. Nucl. Mater. 212-215 (1994) 471-475.

6) Q. Xu, H. Watanabe, T. Muroga, and N. Yoshida, J. Nucl. Mater. 212-215 (1994) 258-262. 
7) H. Matsui, K. Kuji, M. Hasegawa, and A. Kimura, J. Nucl. Mater. 212-215 (1994) 784-789.

8) Q. Xu, H. Watanabe, and N. Yoshida, J. Nucl. Mater. 233-237 (1996) 1057-1061.

9) T. Muroga, S. Ohnuki, F.A. Garner, and S.J. Zinkle, J. Nucl. Mater. 258-263 (1998) 130-139.

10) K. Ochiai, H. Watanabe, T. Muroga, N. Yoshida, and H. Matsui, J. Nucl. Mater. 271-272 (1998) 376-380.

11) N. Yoshida, Q. Xu, H. Watanabe, T. Muroga, and M. Kiritani, J. Nucl. Mater. 191-194 (1992) 1114-1118.

12) S.J. Zinkle, P.J. Maziasz, and R.E. Stoller, J. Nucl. Mater. 206 (1993) 266-286.

13) M. Horiki and M. Kiritani, J. Nucl. Mater. 239 (1996) 34-41.

14) J.T. Busby, G.S. Was, E.A. Kenik, J. Nucl. Mater. 302 (2002) 20-40.

15) Y. Ishiyama, M. Kodama, N. Yokota, K. Asano, T. Kato, K. Fukuya, J. Nucl. Mater. 239 (1996) 90-94.

16) F. Carsughi, H. Ullmaier, H. Trinkaus, W. Kesternich, V. Zell, J. Nucl. Mater. 212-215 (1994) 336-340.

17) W. Van Renterghem, A. Al Mazouzi, S. Van Dyck, J. Nucl. Mater. 413 (2011) 95-102.

18) T. Toyama, Y. Nozawa, W. Van Renterghem, Y. Matsukawa, M. Hatakeyama, Y. Nagai, A. Al Mazouzi, S. Van Dyck, J. Nucl. Mater. 418 (2011) 62-68.

19) K. Fukuya, M. Nakano, K. Fujii, T. Torimaru, Y. Kitsunai, J. Nucl. Sci. Technol. 41 (2004) 1218-1227.

20) W. Van Renterghem, M.J. Konstantinovic, M. Vankeerberghen, J. Nucl. Mater. 452 (2014) 158-165.

21) K. Farrell, T.S. Byun, N. Hashimoto, J. Nucl. Mater. 335 (2004) 471-486

22) N. Hashimoto, T.S. Byun, J. Nucl. Mater. 367-370 (2007) 960-965

23) J.F. Ziegler, M.D. Ziegler, J.P. Biersack, Nucl. Instr. Methods Phys. Res. B 268 (2010) 18181823.

24) D.J. Edwards, E.P. Simonen, S.M. Bruemmer, J. Nucl. Mater. 317 (2003) 13-31.

25) R. Stoenescu, R. Schäublin, D. Gavillet, N. Baluc, J. Nucl. Mater. 360 (2007) 186-195.

26) F. Bergner, A. Ulbricht, P. Lindner, U. Keiderling, L. Malerba, J. Nucl. Mater. 454 (2014) 22-27.

27) Yu.N. Osetsky, D.J. Bacon, A. Serra, B.N. Singh, S.I. Golubov, Phil. Mag. A 83 (2003) 6191

28) J. Marian, B.D. Wirth, R. Schaublin, G.R. Odette, J. Manuel Perlado, J. Nucl. Mater., 323 (2003) 181-191.

29) Yu.N. Osetsky, D.J. Bacon, A. Serra, B.N. Shinh, S.I. Golubov, J. Nucl. Mater. 276 (2000) 65-77. 
Figures and tables

Table 1

Chemical composition of 316L used in this study.

Table 2

Chemical composition of A533B used in this study.

Table 3

Summary of irradiation-induced defects (Frank loops, voids, and black dots) in electronirradiated 316L model alloy before and after heat treatment.

Table 4

Summary of irradiation-induced interstitial type defect feature (black dots and loops) in electronirradiated A533B before and after heat treatment.

Figure 1

History of annealing experiment for 316L electron- irradiated to $1 \mathrm{dpa}$.

Figure 2

History of aging experiment for A533B electron-irradiated to $1 \mathrm{dpa}$.

Figure 3

Microstructural evolution in 316L electron-irradiated to $1 \mathrm{dpa}$ at $290^{\circ} \mathrm{C}$, followed by heating up to $700^{\circ} \mathrm{C}$ and cooling down to $290^{\circ} \mathrm{C}$.

Figure 4

Typical images of voids formed in $316 \mathrm{~L}$ electron-irradiated to $1 \mathrm{dpa}$ at $290^{\circ} \mathrm{C}$, followed by heating up to $700^{\circ} \mathrm{C}$ and cooling down to $290^{\circ} \mathrm{C}$. (Left: under-focus image, Right: over-focus image)

Figure 5

Microstructural evolution in A533B irradiated to $1 \mathrm{dpa}$ at $80^{\circ} \mathrm{C}$, and then, heated up to $500^{\circ} \mathrm{C}$ and cooled down to $80^{\circ} \mathrm{C}$. 
Table 1

\begin{tabular}{|c|c|c|c|c|c|c|c|c|}
\hline $\mathrm{Fe}$ & $\mathrm{Cr}$ & $\mathrm{Ni}$ & $\mathrm{C}$ & $\mathrm{Mo}$ & $\mathrm{Si}$ & $\mathrm{P}$ & $\mathrm{Mn}$ & $\mathrm{S}$ \\
\hline Bal. & 17.11 & 12.24 & 0.011 & 2.03 & 0.44 & 0.020 & 0.79 & 0.001 \\
\hline
\end{tabular}

Table 2

\begin{tabular}{|c|c|c|c|c|c|c|c|c|}
\hline $\mathrm{Fe}$ & $\mathrm{Mn}$ & $\mathrm{Mo}$ & $\mathrm{Ni}$ & $\mathrm{C}$ & $\mathrm{Si}$ & $\mathrm{P}$ & $\mathrm{S}$ & $\mathrm{Cu}$ \\
\hline Bal. & $1.15 / 1.50$ & $0.45 / 0.60$ & $0.40 / 0.70$ & $\leq 0.25$ & $0.15 / 0.30$ & $<0.035$ & $\leq 0.04$ & $<0.003$ \\
\hline
\end{tabular}

Table 3

e- irradiated 316L

\begin{tabular}{|l|c|c|c|c|c|c|}
\hline \multirow{2}{*}{$316 \mathrm{~L}$} & \multicolumn{3}{|c|}{ as-irradiated to 1 dpa } & \multicolumn{3}{c|}{ after annealing } \\
\cline { 2 - 7 } & Frank loop & Void & Black dot & Frank loop & Void & Black dot \\
\hline Mean diameter $/ \mathrm{nm}$ & $17.2 \pm 0.5$ & $2.4 \pm 0.5$ & $4.4 \pm 0.5$ & $3.1 \pm 0.5$ & $4.1 \pm 0.5$ & $3.0 \pm 0.5$ \\
\hline Number density $/ \mathrm{m}^{-3}$ & $2.8 \pm 0.5 \times 10^{22}$ & $3.2 \pm 0.5 \times 10^{22}$ & $1.0 \pm 0.5 \times 10^{22}$ & $<1.0 \times 10^{22}$ & $2.2 \pm 0.5 \times 10^{22}$ & $1.0 \pm 0.5 \times 10^{21}$ \\
\hline
\end{tabular}

Table 4

e- irradiated A533B

\begin{tabular}{|c|c|c|c|c|}
\hline \multirow{2}{*}{ A533B } & as-irradiated to 1 dpa & \multicolumn{3}{|c|}{ after aging } \\
\cline { 2 - 5 } & $80^{\circ} \mathrm{C}$ & $400^{\circ} \mathrm{C}$ & $450^{\circ} \mathrm{C}$ & $500^{\circ} \mathrm{C}$ \\
\hline Mean diameter $/ \mathrm{nm}$ & $17.2 \pm 0.5$ & $6.0 \pm 0.5$ & $8.0 \pm 0.5$ & $5.0 \pm 0.5$ \\
\hline Number density $/ \mathrm{m}^{-3}$ & $2.8 \pm 0.5 \times 10^{22}$ & $2.0 \pm 0.5 \times 10^{21}$ & $2.0 \pm 0.5 \times 10^{21}$ & $3.0 \pm 0.5 \times 10^{21}$ \\
\hline
\end{tabular}


Figure 1

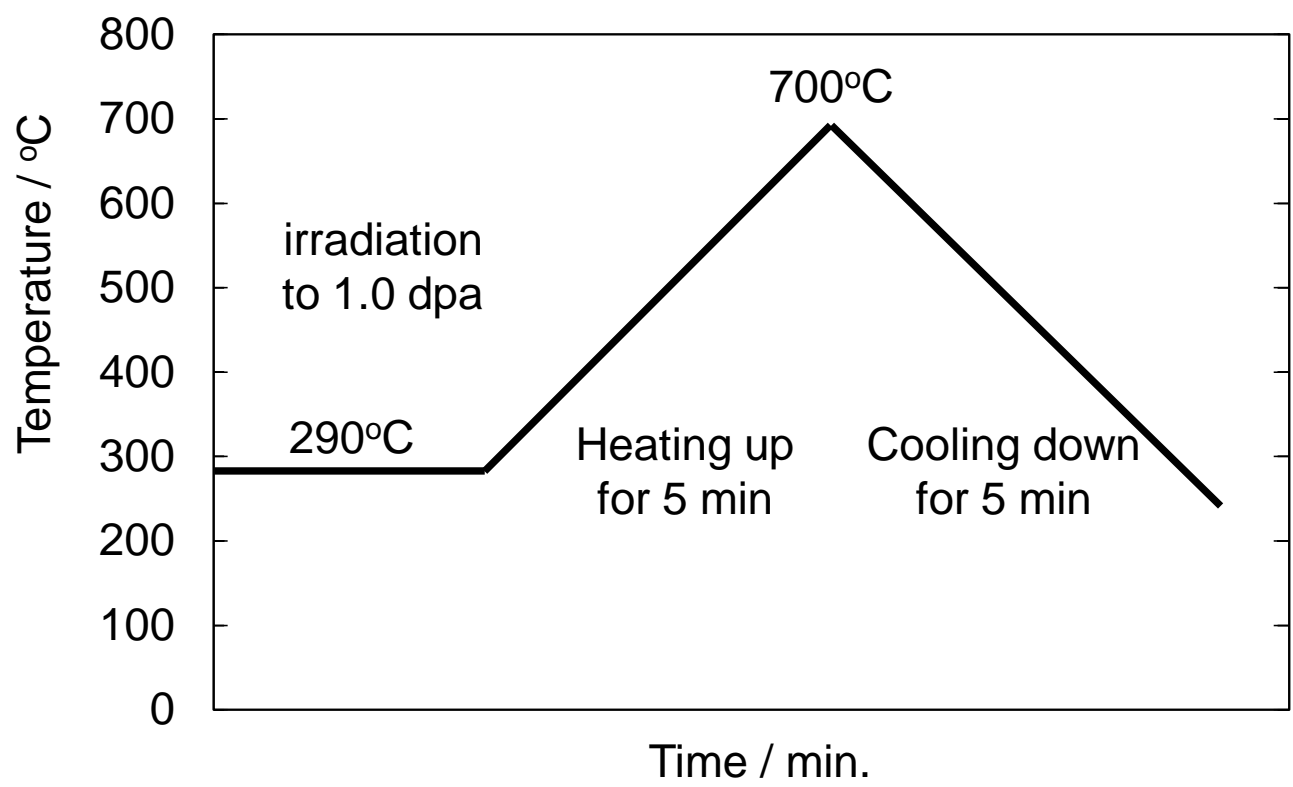


Figure 2

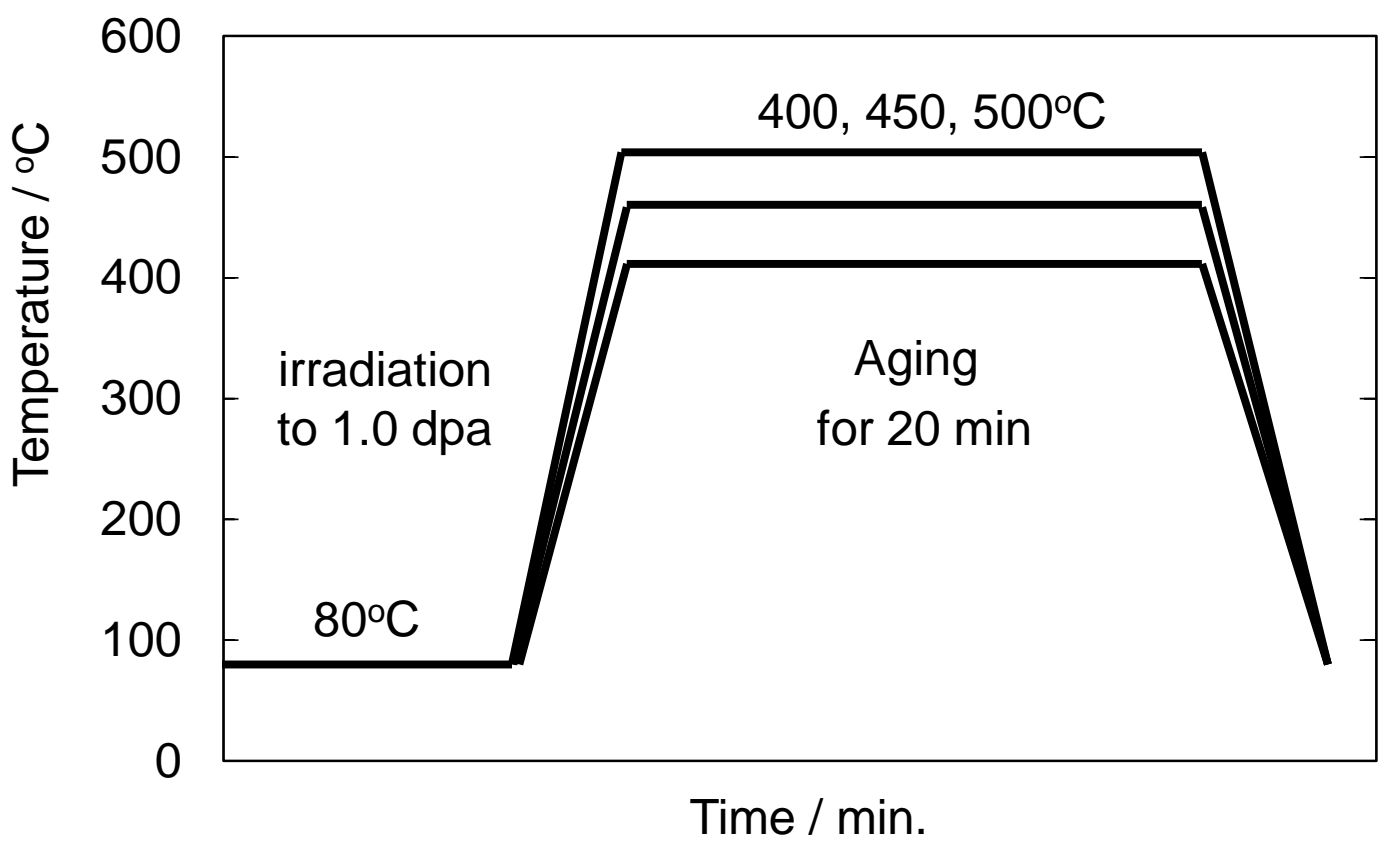


Figure 3

As-irrad. at $290^{\circ} \mathrm{C}$

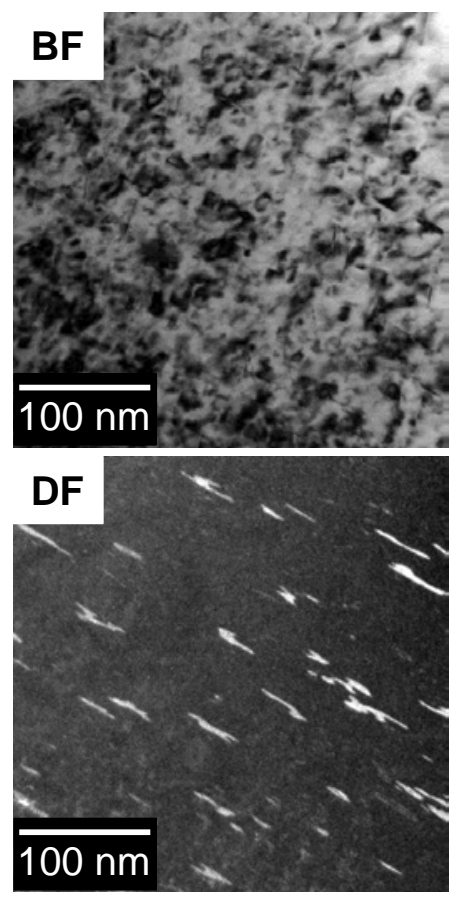

Heated up to $700^{\circ} \mathrm{C}$ for $5 \mathrm{~min}$.

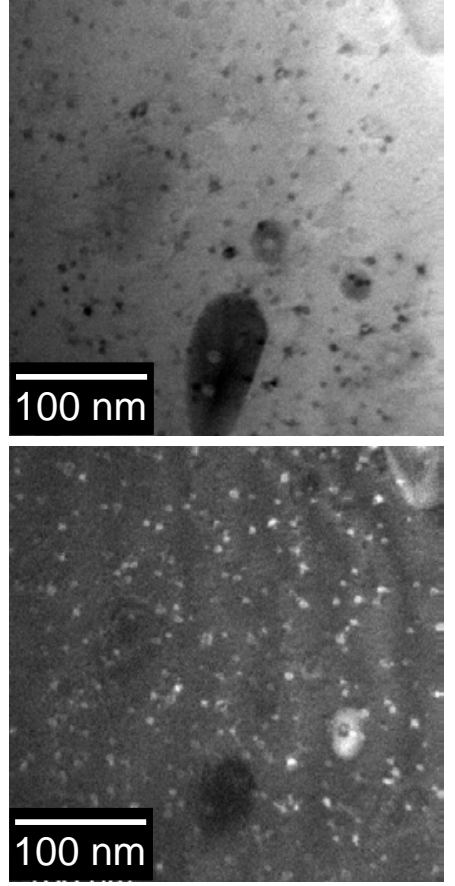

Cooled down to $290^{\circ} \mathrm{C}$ for $5 \mathrm{~min}$.

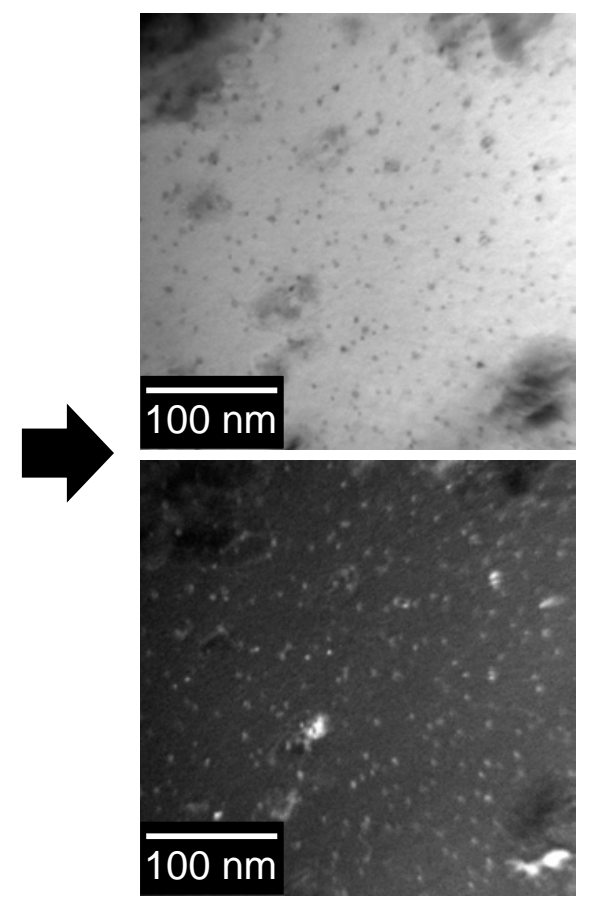


Figure 4

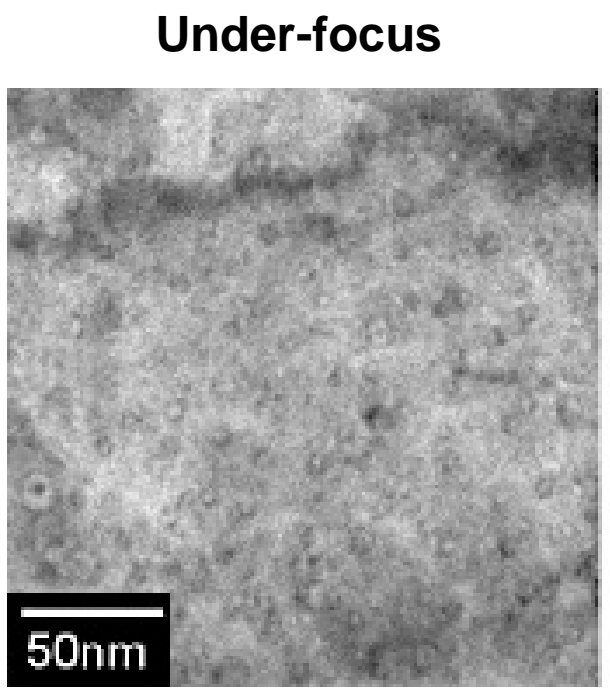

Over-focus

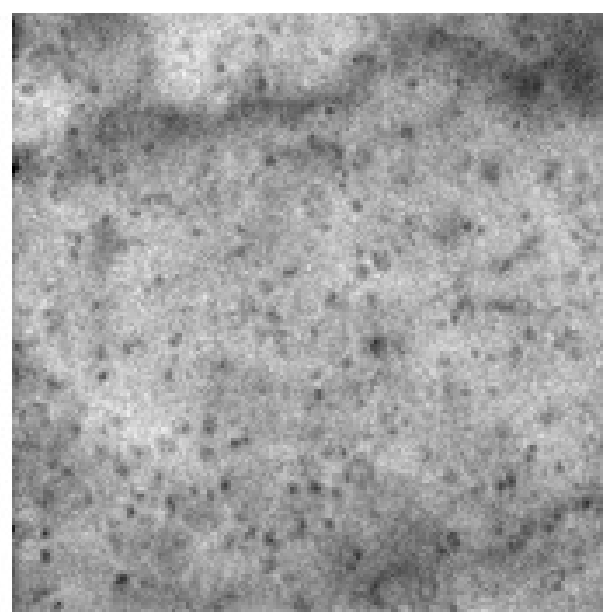


Figure 5

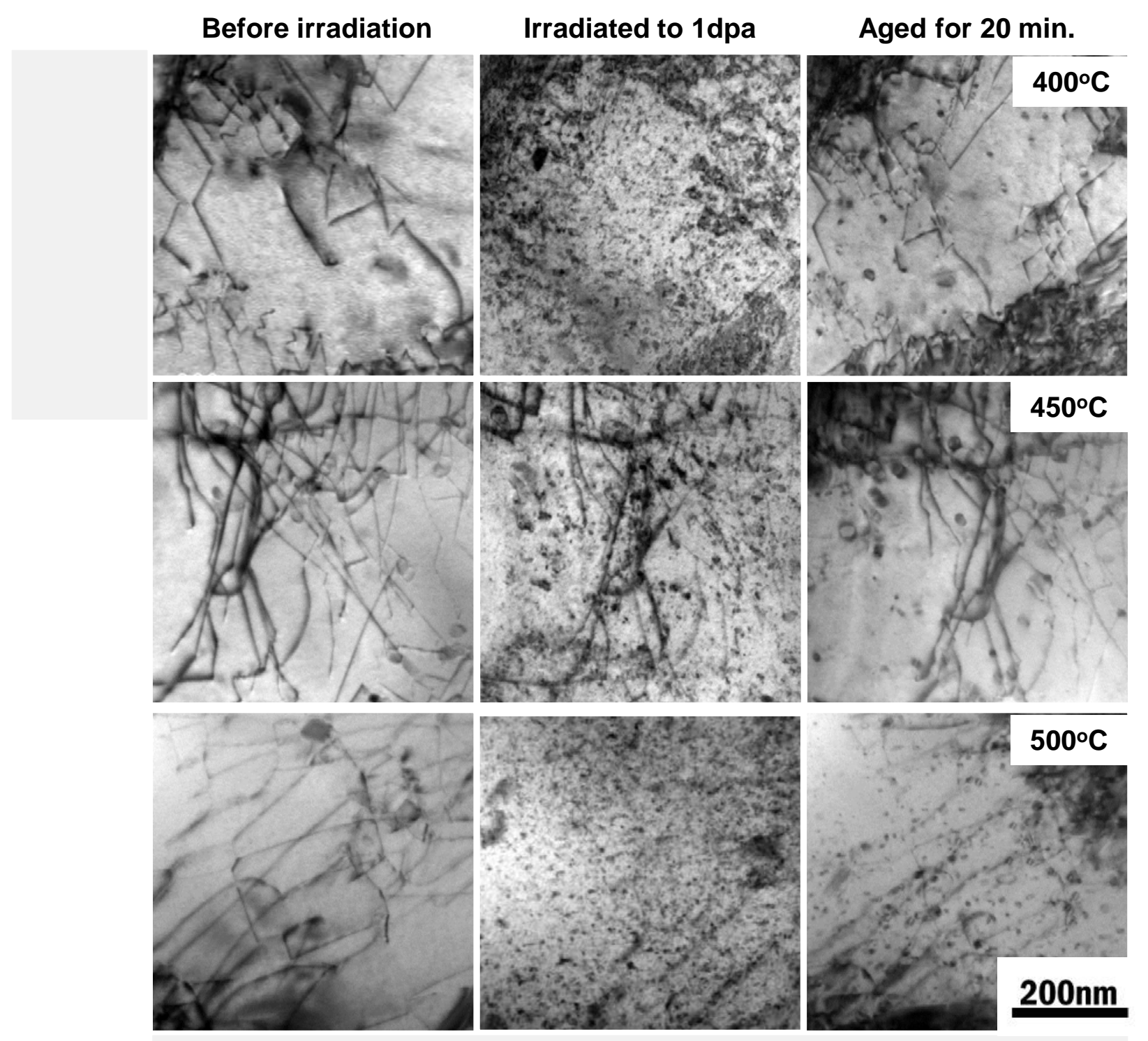

